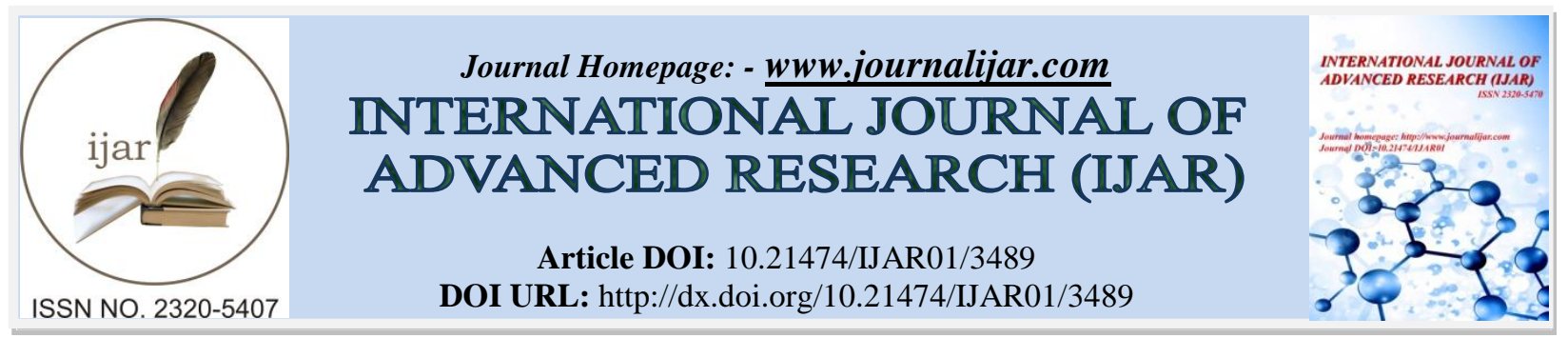

RESEARCH ARTICLE

\title{
SERUM TOTAL CALCIUM, MAGNESIUM, POTASSIUM AND PH IN SUDANESE PATIENTS WITH TYPE 2 DIABETES MELLITUS.
}

Nuha Eljaili Abubaker ${ }^{1}$ and Mohammed Nasir Mohammed ${ }^{2}$.

1. College of Medical Laboratory Science, Sudan University of Science and Technology (Assistant professor).

2. Elneelin University, Collage of Medical Laboratory Science.

\section{Manuscript Info}

Manuscript History

Received: 04 January 2017

Final Accepted: 06 February 2017

Published: March 2017

\section{Abstract}

This study was carried out to measure serum levels of the calcium, magnesium, potassium and PH in patients with type 2 DM. Sixty samples were collected from patients in period between October to November 2016, chosen randomly from Military hospital and Sixty apparently, healthy individuals as controls, to assess the levels of calcium, magnesium, Potassium and $\mathrm{pH}$ in type2 D M.

Serum calcium and magnesium were measured by using automation, Mindray380, potassium by using easylyte and $\mathrm{pH}$ by using Cobas $\mathrm{b}$ 221, and results were analyzed using statistical of package social science (SPSS), computer program.

The study showed that, the serum levels of magnesium and potassium were significantly decreased, (p-value $=0.00$ ) in diabetic patients compared to control group. While the level of PH was significantly increased, $(p$-value $=0.000)$ and there was no significant difference between the mean of calcium level in patients and control group. Mean $\pm \mathrm{SD}$ cases versus control. (1.43 \pm 0.26 versus $2.10 \pm 0.29)$ For magnesium. $(3.1 \pm 0.39$ versus $4.10 \pm 0.48)$ for potassium.

( $7.99 \pm 0.06$ versus $7.40 \pm 0.02)$ for $\mathrm{PH}$.

$(8.77 \pm 1.00$ versus $8.79 \pm 0.80, \mathrm{p}$-value $=0.997)$ for calcium.

There was insignificantly weak positive correlation between serum magnesium in patients used insulin and diabetic patients not used insulin ( $\mathrm{r}=0.1 / \mathrm{p}=0.627$ ), while there were no correlations between serum calcium, potassium and $\mathrm{PH}$ in diabetic patients used insulin and diabetic patients not used insulin. $(\mathrm{r}=0.073, \mathrm{p}$ - value $=0.70),(\mathrm{r}=0.027$, $\mathrm{p}$ - value $=0.888),(\mathrm{r}=0.08, \mathrm{p}$-value $=0.676)$ respectively.

It is concluded that; the levels of magnesium and potassium are significantly decreased in patients with type $2 \mathrm{DM}$, and the level of PH is significantly increased and there is no significant difference in the level of calcium in type 2 diabetic patients compared to control group.

Copy Right, IJAR, 2017,. All rights reserved.

\section{Introduction:-}

Diabetes mellitus is characterized by hyperglycemia due to absolute or relative deficiency of insulin ${ }^{(1)}$, leading to impaired metabolism of carbohydrates, proteins, fats, water and electrolytes. The persistence of these metabolic disturbances lead to permanent and irreversible functional and structural changes in the cells of the body which in 
turn lead to the development of "diabetic complications", characteristically affecting, the cardiovascular system, eye, kidney and nervous system mainly ${ }^{(2)}$. A relationship between DM and minerals is frequently reported. Alteration in the metabolism of trace elements like calcium, magnesium is associated with $\mathrm{DM}^{(3)}$. Trace elements are accepted as essential for optimum health, because of their diverse metabolic characteristic and functions ${ }^{(4)}$. Trace elements participate in production of reactive oxygen species (ROS), which contribute to oxidative stress. Oxidative stress contributes to the pathogenesis of many diseases including DM. Chronic complications of diabetes mellitus can be divided into vascular and nonvascular complications. The vascular complications of DM are further subdivided into micro vascular (retinopathy, neuropathy, nephropathy) and macro vascular complications coronary artery disease, peripheral arterial disease, cerebrovascular disease ${ }^{(5)}$. Several of the complications of diabetes may be related to increased intracellular oxidants and free radicals ${ }^{(6)}$.

Magnesium, calcium and potassium are an essential element involved in glucose homeostasis. It is a cofactor for various enzymes in carbohydrate metabolism. It is also involved at multiple levels in insulin secretion, binding and activity. Reduced level of magnesium has been documented in type $2 \mathrm{DM}^{(3,4,7 \text { and } 8)}$. Hypomagnesaemia may have negative impact on glucose homeostasis and insulin sensitivity in type 2 DM patients ${ }^{(9)}$. Hypomagnesaemia may also have some effect in the development of diabetic complications with other risk factors ${ }^{(10)}$. The present study was designed to evaluate the serum levels of potassium; magnesium and calcium in type 2 DM.

\section{Material and methods:-}

Study Population The study was carried out at College of Medical laboratory Science and the subjects were recruited from military hospital in Khartoum from period between October to November 2016. A total of 60 type 2 DM and 60 apparently, healthy individuals as controls were enrolled in this study. The study was approved by hospital's ethics committee. Informed consent was obtained from patients before blood sampling.

\section{Inclusion criteria:-}

Sudanese patients with type $2 ` \mathrm{DM}$ and apparently healthy volunteers (matches age and sex with the cases) were included.

Exclusion criteria: patients with hypertension, renal disease, heart disease and other disease related to $\mathrm{pH}$ imbalance were excluded.

\section{Blood sample and analysis:}

About $2 \mathrm{ml}$ of venous blood was collected from the antecubital vein by taking aseptic precautions. Care was taken to prevent venous stasis during the sample collection. The blood was allowed to clot and the serum was separated by centrifugation. The estimation of the parameters was carried out within 4-6 hrs. The samples were analyzed for serum calcium and magnesium by using automation, Mindray $380^{(11)}$, potassium by Electrolyte analyzer (easylyte) and $\mathrm{pH}$ by using Cobas b $221^{(12)}$. The internal control sera of two different levels were used to calibrate the instruments.

Data was analyzed using SPSS computer program, the mean and standard deviation were obtained and the independent 't.test' used for comparison ( $p$ value of $\leq 0.05$ ) was considered significant.

\section{Results:-}

In comparison with the controls, diabetic patients (type2) had significantly lower in means serum magnesium and potassium $\quad(1.43 \pm 0.26$ versus $2.10 \pm 0.2951 \mathrm{mg} / \mathrm{dL}),(3.1 \pm 0.39$ versus $4.10 \pm 0.48 \mathrm{mmol} / \mathrm{L}) \quad \mathrm{p}$ value $<0.05$ respectively. There was significant increase in mean of $\mathrm{PH}$ in type $2 \mathrm{DM}$ compared to control group (7.99 \pm 0.06 versus $7.40 \pm 0.02) \mathrm{p}$ value $<0.05$. There was insignificant difference in mean serum calcium compared to control group $(8.77 \pm 1.00$ versus $8.79 \pm 0.80, \mathrm{p}$-value $=0.997) \quad \mathrm{p}$-value $\geq 0.05$ as in table 1 . 
Table (1):- means comparisons of serum calcium, magnesium, potassium and $\mathrm{PH}$ in type 2 diabetes mellitus compared to control group.

\begin{tabular}{|l|l|l|l|}
\hline Variable & $\begin{array}{l}\text { Patients } \\
(\text { mean } \pm \text { SD) } \\
\mathrm{N}=60\end{array}$ & $\begin{array}{l}\text { Control } \\
(\text { mean } \pm \text { SD) } \\
\text { N=60 }\end{array}$ & P-value \\
\hline Calcium $(\mathrm{mg} / \mathrm{dL})$ & \multicolumn{1}{|c|}{$8.77 \pm 1.00$} & $8.79 \pm 0.80$ & 0.997 \\
\hline Magnesium $(\mathrm{mg} / \mathrm{dL})$ & $1.43 \pm 0.26$ & $2.10 \pm 0.29$ & 0.000 \\
\hline Potassium $(\mathrm{mmol} / \mathrm{L})$ & $3.10 \pm 0.39$ & $4.17 \pm 0.48$ & 0.000 \\
\hline PH & $7.99 \pm 0.06$ & $7.40 \pm 0.02$ & 0.000 \\
\hline
\end{tabular}

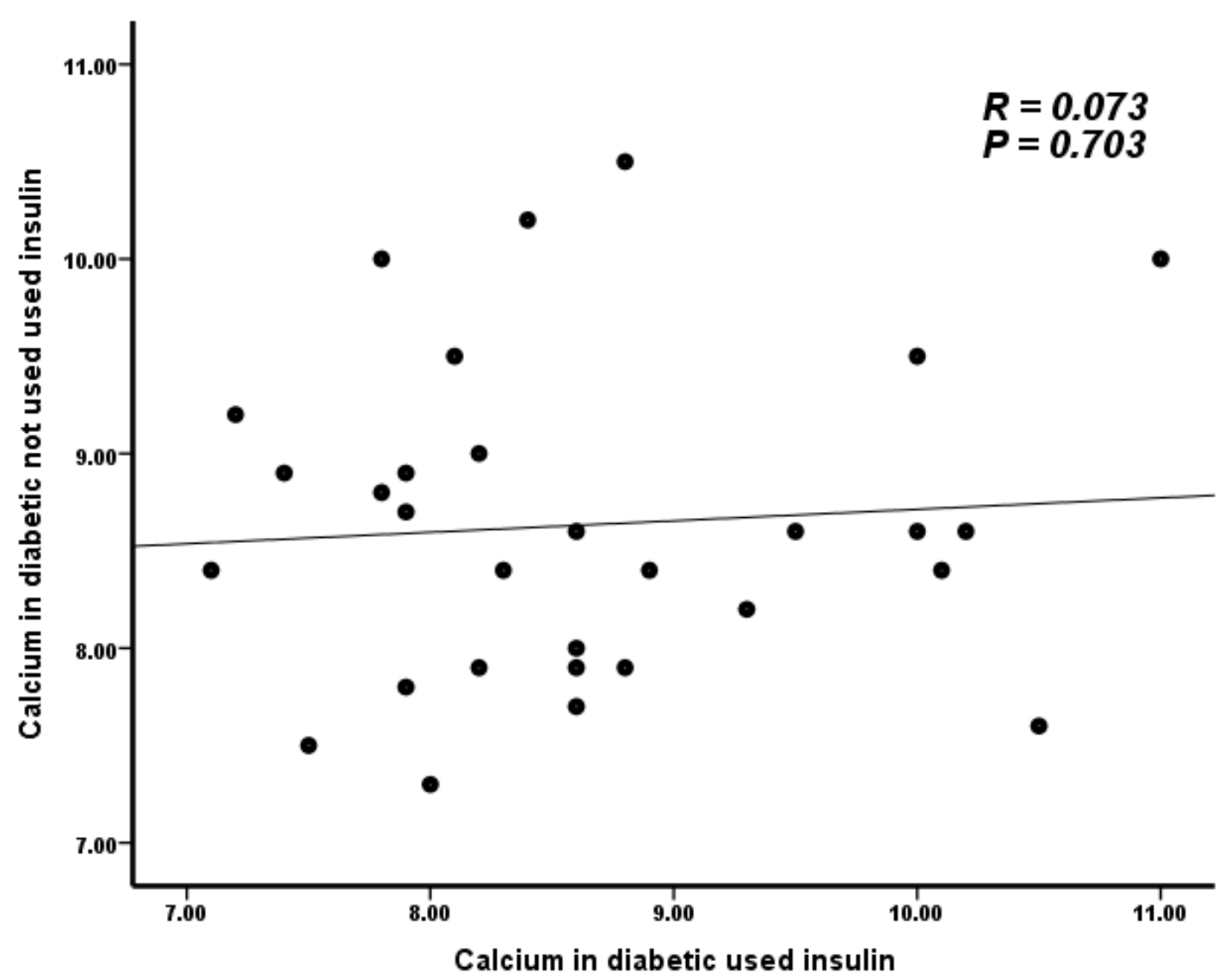

Figure (1):- A scatter plot shows the correlation between calcium level in diabetic patients used insulin and diabetic patients not used insulin ( $\mathrm{r}=0.073$, $\mathrm{p}$-value $=0.703$ ).

There is no correlation between calcium level in diabetic patients used insulin and diabetic patients not used insulin. 


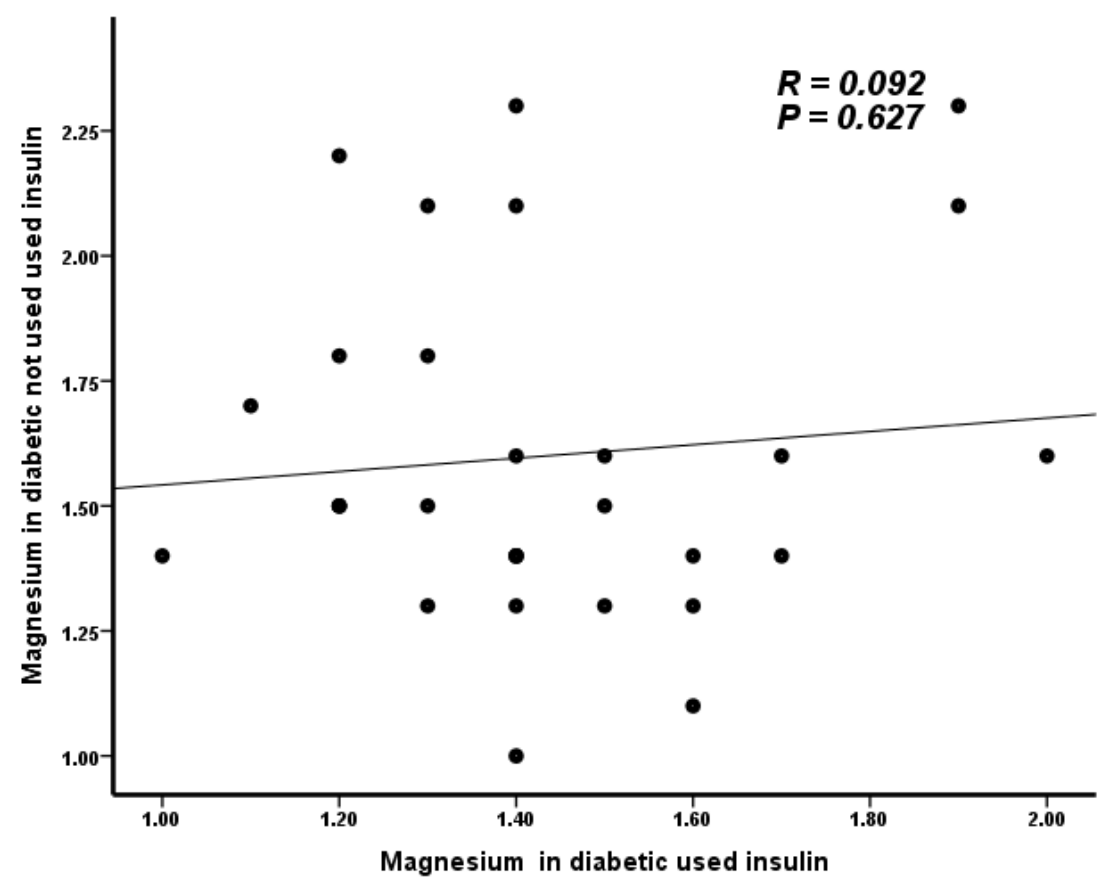

Figure (2):- A scatter plot shows the correlation between magnesium level in diabetic patients used insulin and diabetic patients not used insulin $(r=0.092$, $\mathrm{p}$-value=0.627).

There is weak positive correlation between magnesium level in diabetic patients used insulin and diabetic patients not used insulin.

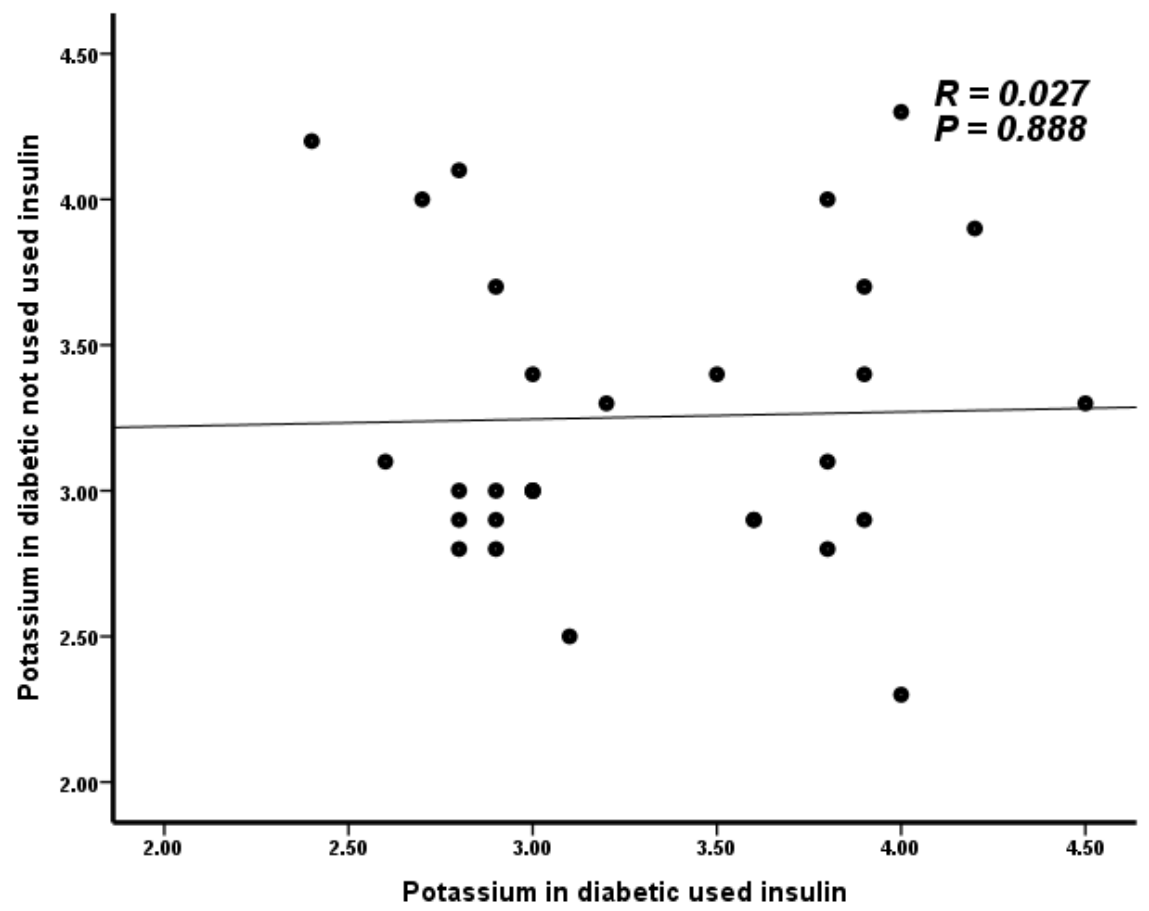

Figure (3):- A scatter plot shows the correlation between Potassium level in diabetic patients used insulin and diabetic patients not used insulin $(\mathrm{r}=0.027$, $\mathrm{p}$-value=0.888).

There is no correlation between potassium level in diabetic patients used insulin and diabetic patients not used insulin. 


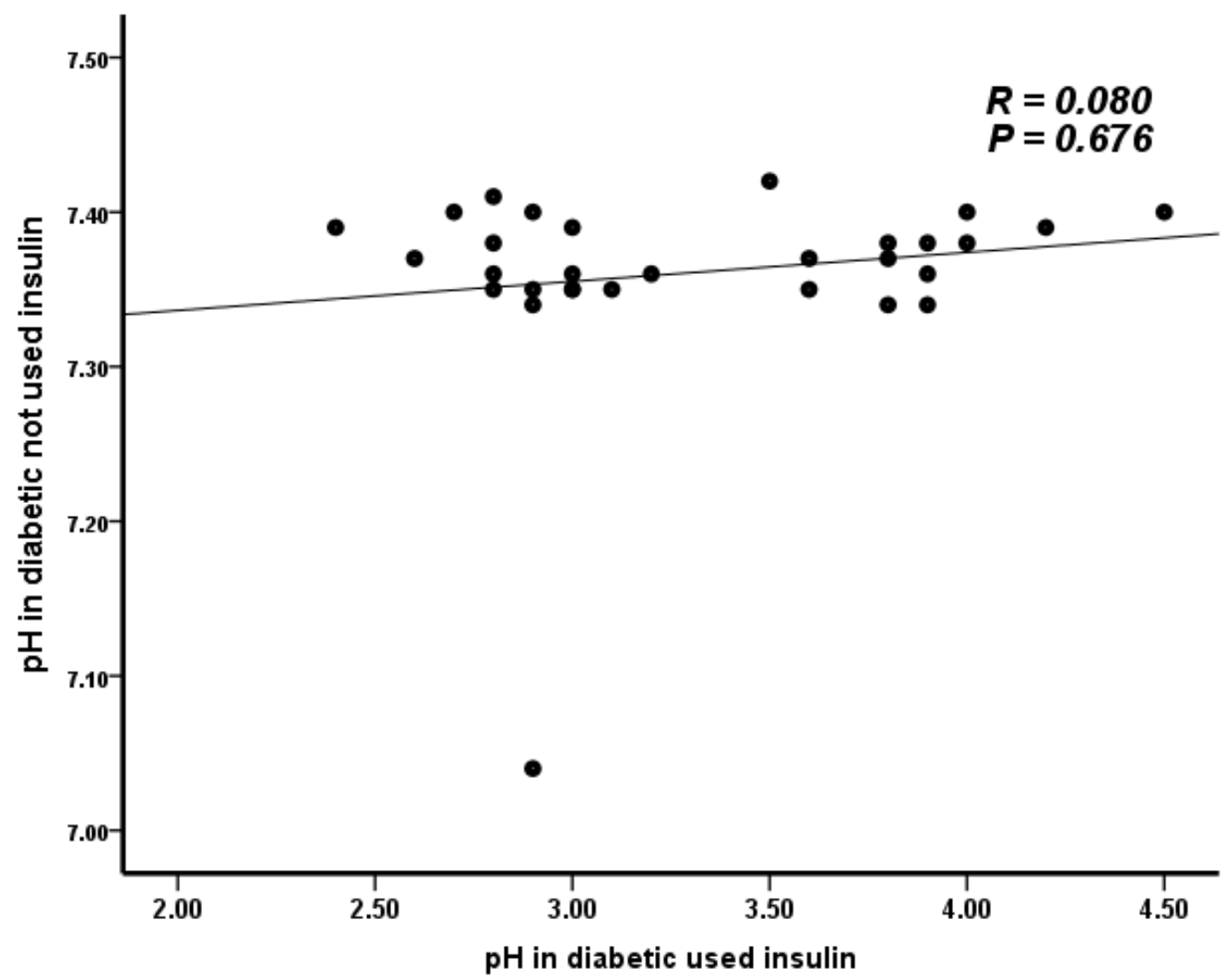

Figure (4):- A scatter plot shows the correlation between $\mathrm{pH}$ level in diabetic patients used insulin and diabetic patients not used insulin $r=0.080$, $p$-value $=0.676$ ).

There is no correlation between $\mathrm{pH}$ level in diabetic patients used insulin and diabetic patients not used insulin.

\section{Discussion:-}

A relationship between DM and minerals is frequently reported. Alteration in the metabolism of trace elements like calcium, magnesium potassium is associated with DM ${ }^{(3)}$. Trace elements are accepted as essential for optimum health, because of their diverse metabolic characteristic and functions ${ }^{(4)}$. Trace elements participate in production of reactive oxygen species (ROS), which contribute to oxidative stress. Oxidative stress contributes to the pathogenesis of many diseases including DM.

Results in this study found that, the serum levels of magnesium and potassium were significantly decreased in diabetic patients compared to control group. This results agree with another results carried by many authors ${ }^{(13,14)}$, which finding confirmed that, there were significantly decreased in mean of serum magnesium and potassium in diabetic patients compared to control group, $(\mathrm{p}$-value $=0.00)$. Also this study was in agreement with another study done by (Puri etal. , 2013), which showed hypomagnesaemia and hypokaleamia in diabetic patients and this may be a possible risk factor in development and progress of diabetic complications.

Also the results agree with another result which showed, Hypomagnesemia has been reported to occur at an increased frequency among patients with type 2 diabetes compared with their counterparts without diabetes ${ }^{(15)}$. Hypomagnesemia has been linked to poor glycemic control, coronary artery diseases, hypertension, diabetic retinopathy, nephropathy, neuropathy, and foot ulcerations. This study in agreement with another study, which finding confirm that, hypokalemia may reduce $\mathrm{Na}^{+}-\mathrm{K}^{+}-2 \mathrm{Cl}^{-}$co-transport activity, the associated potassium extrusion through the potassium channel ROMK, and resultant diminution of the favorable trans membrane voltage that is required for paracellular $\mathrm{Mg}$ reabsorption. In addition, there is evidence to suggest that cellular potassium depletion may diminish Mg reabsorption at the DCT by yet unclear mechanisms. ${ }^{(16)}$

The result showed, the level of PH was significantly increased (p-value $<0.05$ ) and there was no significant difference between the mean of calcium level in patients and control group ( $\mathrm{p}$-value $>0.05$ ). 
This result disagreed with another result, which showed Diabetes Mellitus is known to have its effect on almost all body system through alterations in structural and biochemical changes in tissues, alteration in calcium flux may adversely affect the insulin secretion as it is a calcium dependent process. ${ }^{(17)}$

There was insignificantly weak positive correlation between serum magnesium in diabetic patients used insulin and diabetic patients not used insulin $(r=0.1, p=0,627)$. This result in agreement with result carried by researchers at the Institute of Internal Medicine, University of Palermo wrote, "Intracellular magnesium concentration has also been shown to be effective in modulating insulin action (mainly oxidative glucose metabolism). A poor intracellular $\mathrm{Mg}$ concentration, as found in noninsulin-dependent diabetes mellitus (NIDDM) and in hypertensive patients, may result in a defective tyrosine-kinase activity at the insulin receptor level. ${ }^{(18)}$ There were no correlations between serum calcium, potassium and $\mathrm{PH}$ in diabetic patients used insulin and diabetic patients not used insulin.( $\mathrm{r}=0.073$, $\mathrm{p}$ value $=0.70),(\mathrm{r}=0.027, \mathrm{p}$ - value $=0.888),(\mathrm{r}=0,08, \mathrm{p}$-value $=0.676)$ respectively.

\section{Referance:-}

1. Alberti , K.G ., Zimmet, P.Z. WHO consultation. Definitions, diagnosis and complications. Part 1.Diabetic Med. 1998; 15:529-533.

2. Koda-Kimble, M.A., Carlisle, B.A. Diabetes mellitus. In :Young LY, Koda-Kimble MA, Kradjan WA, Guglielmo BJ, editors. Applied therapeutics: the clinical use of drugs. 6th ed. Vancouver (WA): Applied therapeutics. 1995;48:481-5.

3. Viktorínová, A., Toserová, E., Krizko., M, Durackova , Z., Altered metabolism of copper, zinc, and magnesium is associated with increased levels of glycated hemoglobin in patients with diabetes mellitus. Metabolism. 2009; 58:1477-1482.

4. Zargar ,A.H., Shah, N.A., Masoodi, S.R., Laway, B.A., Dar, F.A., Khan, A. Copper, zinc and magnesium levels in non-insulin dependent diabetes mellitus. Postgrad Med J 1998; 74:665-668.

5. Ankush,R.D., Suryakar, A.N., Ankush, N.R. Hypomagnesaemia in type-2 diabetes mellitus patients: a study on the status of oxidative and nitrosative stress. Ind J ClinBiochem 2009; 24:184-189.

6. Evliyaoglu, O., Kebapcilar, L., Uzuncan, N., Kılıçaslan, N., Karaca, B., Kocaçelebi, R. Correlations of serum $\mathrm{Cu}+2, \mathrm{Zn}+2, \mathrm{Mg}+2$ and $\mathrm{HbA1c}$ in Type 1 and Type 2 Diabetes Mellitus. Turkish Journal of Endocrinology and Metabolism.2004; 2: 75-79.

7. Hussain, Maan ,M.A., Sheikh, M.A., Nawaz, H., Jamil, A. Trace elements status in type 2 diabetes. Bangladesh Journal of Medical Science. 2009; 8:44-45

8. Pham, P.C., Pham, P.M., Pham, S.V., Miller, J.M.. Hypomagnesemia in Patients with Type 2 Diabetes. Clin J Am SocNephrol. 2007; 2: 366-373

9. Power,A.C. Diabetes mellitus. In Braunald, E., Fauci, A.S., Kasper, D.L., Hauser, S.L., Longo, D.L., Jameson J.L., editors. Harrison's Principles of Internal Medicine. 17th ed. New York. McGraw Hill: 2286.

10. Chausmer,A.B. Zinc, insulin and diabetes. J Am College of Nutr.1998; 17(2):109-115

11. Giteman, H. J. An improved procedure for the determination of calcium in biochemical specimens. Anal Biochem. 1967; 18:521-531.

12. Gindler, E. M and Heth, D. A. Colorimetric determination with bound "Calmagite" of Magnesium in human blood serum. ClinChem 1971; 17:662.

13. Ramachandra Prabhu, H.D. Serum Magnesium and HbA1c in Type 2 Diabetes Mellitus Patients. International Journal of Science and Research (IJSR). 2013:6-14.

14. Khalil, F. M .plasma magnesium in type 2 diabetic patients with and without diabetic neuropathy. International Journal of Advanced research (IJAR).2016;4(10): 2166-2170.

15. Puri, M. Comparative of type 2 diabetes mellitus with and without microangiopathic complications.Innovatine. Journal of medical and health science: 2013: 274-278

16. Sanders, G.T, Huijgen, H.J., Sanders, R. Magnesium in disease: A review with special emphasis on the serum ionized magnesium. Clin Chem Lab Med. 199937 :1011- 1033.

17. Dai ,L.J., Friedman, P.A., Quamme, G.A.. Cellular mechanisms of chlorothiazide and potassium depletion on Mg2+ uptake in mouse distal convoluted tubule cells. Kidney Int51, $1997: 1008-1017$.

18. Kanchana, $\mathbf{N}$ and Saikumar, P. Serum Calcium Levels In Type 2 Diabetes Mellitus. Journal of Dental and Medical Sciences (IOSR-JDMS), 2014; 13(8) : 01-03.

19. Barbagallo , M., Dominguez, L.J., Galioto, A., Ferlisi, A., Cani, C., Malfa, L., Pineo, A., Busardo, A., Paolisso, G. Role of magnesium in insulin action, diabetes and cardio-metabolic syndrome . Institute of Internal Medicine and Geriatrics, University of Palermo, Palermo, Italy. 2003 ; 24(3):39-52. 